\title{
Workshop
}

\section{Reflective Writing as an Assessment for Student Analysis and Synthesis Ability in a Landscape Design Course}

\author{
Ann Marie VanDerZanden ${ }^{1}$
}

ADDITIONAL INDEX WORDs. teaching, critical thinking, Bloom's taxonomy, curriculum

SUMMARY. Horticulture graduates entering the field of landscape design and installation must be able to integrate technical skills with practical applications. This requires higher-order thinking skills such as critical thinking, which can be practiced through various teaching and learning strategies in an undergraduate curriculum. The objective of this project was to develop a series of three reflective writing assignments in a landscape design course to help students improve their critical thinking skills of analysis and synthesis. Scores on an 18-point quiz question for 110 students enrolled in Beginning Garden Composition (HORT 380) from 2005 to 2009 were compared. The comparison was between 2 years when the reflective writing assignments were not part of the course and 3 years when the assignments were included in the course. Quiz scores increased significantly for the students who completed the reflective writing assignments (average of 16.2 out of 18 ) compared with students who did not complete the assignments as part of the course (average 10.2 out of 18 ).

$\mathrm{L}$ andscape design and installation is a fast-growing and profitable segment of the horticulture industry (Landscape Management, 2003). As the landscape profession grows and becomes more sophisticated, the demand for employees who can integrate technical knowledge with practical application increases (Beidler et al., 2006; Berle, 2007). Providing opportunities for students to develop these skills is an essential part of their undergraduate education.

One way to help students develop higher-order thinking skills, those that require synthesis, application, and evaluation, is to integrate

Professor, Department of Horticulture, Iowa State University, 106 Horticulture Hall, Ames, IA 50011

${ }^{1}$ Corresponding author. E-mail: vanderza@iastate.edu.
Bloom's Taxonomy (Bloom et al., 1956) into the curriculum (McCormick and Whittington, 2000; VanDerZanden, 2005). Bloom's taxonomy is a classification method for thinking behaviors and includes the cognitive domain (knowledge-based), the affective domain (attitudinal-based), and the psychomotor domain (skills-based) (Bloom et al., 1956). To ascend through the hierarchical taxonomy requires more complex thinking. Through this system students move from activities that show knowledge, comprehension, and application to those that require them to analyze, synthesize, and evaluate (Fig. 1).

Research suggests that reflective writing can be an effective teaching method in agriculture-related fields (Boyd et al., 2006; Lindner et al.,
2002; Moss et al., 2002). Reflective writing assignments can be used to help the learner construct meaning from information and experiences (Boyd et al., 2006; Litke, 2002) and requires students to use the higher-order thinking skills indicated in Bloom's taxonomy. Hatton and Smith (1995) identified four types of reflective writing that move from the lowest level of descriptive writing to the highest level of in-depth critical reflection. Each level provides different benefits for the student writer and all are fundamental to the reflection and learning process (Walkington et al., 2001).

The objective of this study was to develop and evaluate a series of three reflective writing assignments. Through these assignments students apply technical content covered in a course as well as their own background and experiences to short writing assignments related to landscape design.

\section{Course description}

Beginning Garden Composition (HORT 380) is a two-credit course that has two 50-min sessions per week and is offered each spring semester at Iowa State University (ISU). The course covers the basics of landscape design, including site inventory and analysis, the landscape design process, the principles of landscape design, landscape preference, plant and hardscape selection, and a review of the design impact from historical eras (2000 B.C. to the early 1900s). Students have junior or senior standing, and the majority has been horticulture students in the landscape design, installation, and management option. Additional students include those from

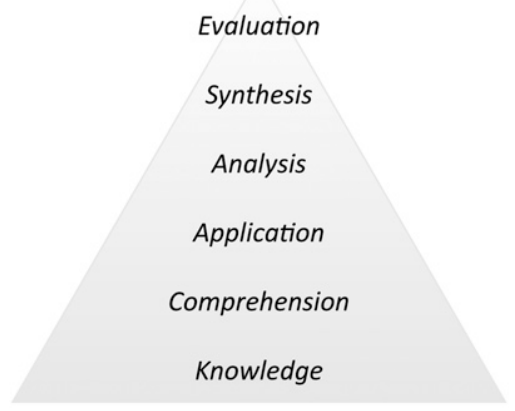

Fig. 1. Visual representation of Bloom's taxonomy hierarchical classification for thinking behaviors. 
other options within the Department of Horticulture or students enrolled in the ISU landscape architecture program (Table 1). The average enrollment is 22 students per semester and the instructor has taught the course for 12 semesters. The reflective writing assignments described in this article have been a component of the course for three semesters $(2007,2008$, and 2009).

\section{Materials and methods}

Students completed a series of three reflective writing assignments related to a residential landscape image (Fig. 2). The first assignment, completed after Week 2 of the semester, required students to describe the landscape image in as much detail as possible. The second assignment, completed after Week 7 , required students to describe how the seven principles of design, previously discussed in class, were evidenced in the landscape image.
The third assignment was completed after Week 12 and at the conclusion of 4 weeks of class discussion about historical eras of landscape design. In this third assignment, students described how historical garden eras influenced the landscape image.

During Week 8 of the course, students took a 50-point quiz, which included a question related to the second reflective writing assignment. The quiz question was worth 18 points and read as "Study the landscape plan below. List and describe how the seven principles of design are expressed in this landscape design." The quiz question related to the plan view landscape image in Figure 3.

Data on the quiz question were collected from 110 students enrolled in this course from spring semester 2005 through spring semester 2009 $(\mathrm{n}=23$ in $2005, \mathrm{n}=20$ in $2006, \mathrm{n}=$ 22 in $2007, \mathrm{n}=24$ in $2008, \mathrm{n}=21$ in 2009). Data were entered using Excel

Table 1. Academic standing and major or option for students enrolled in the Beginning Garden Composition (HORT 380) course at Iowa State University spring semesters 2005 to 2009.

Students (no.)

Academic standing

Junior

Senior

Total

\section{Students' major or option}

Landscape Design, Installation and Management (option)

Turfgrass Management (option)

Nursery Production and Management (option)

Landscape Architecture (major)

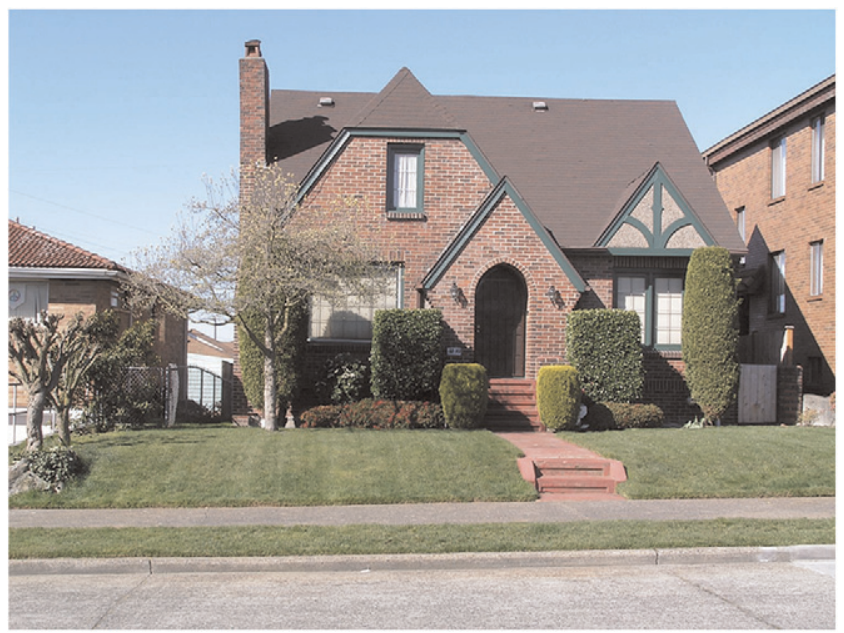

Fig. 2. Landscape image used for three reflective writing assignments in Beginning Garden Composition (HORT 380) at Iowa State University.
(Microsoft, Redmond, WA) and subjected to descriptive statistics.

\section{Results and discussion}

Figure 4 illustrates average student scores on the quiz question when the reflective writing assignment was not included in the course (2005, 2006) and when it was included (2007, 2008, 2009). The significant increase in scores when the assignments were included in the curriculum suggests the reflective writing assignments are an effective method to enhance the critical thinking skills of analysis and synthesis in landscape design.

Furthermore, when students were asked to describe their experience with the writing assignments, many noted that the writing helped them connect what was covered in lecture with an actual landscape design. Examples of students' comments include “...when coming into this class I already knew most of the design principles and how they related to one another; however, I knew very little about the eras of gardening. This reflection assignment taught me many things about gardens and where different ideas originated from." Another student wrote "... at first glance it appears to be a typical residential landscape, but now I see how the ancient Egyptians, the Romans and the Italian Renaissance impacted the shrubs around the front door." After completing the third reflective writing assignment, one student wrote "Overall, the knowledge I gained in these assignments has helped me understand the purpose for gardens used by all kinds of civilizations. Gardens have mainly focused around themes of functionality, pleasure and symbolism. This knowledge will help me focus on how to design a garden that will meet these three themes."

As a result of the significant increase in scores on the quiz question, two additional reflective writing assignments will be added to the course in Spring 2010. One assignment will address the concept of blending form and function in a landscape, and the second will relate to strategies for designing sustainable landscapes.

Helping students enhance critical thinking and communication skills is important to their future success in the landscape horticulture industry. With some planning and preparation, the reflective writing assignments described in this article can be incorporated into 


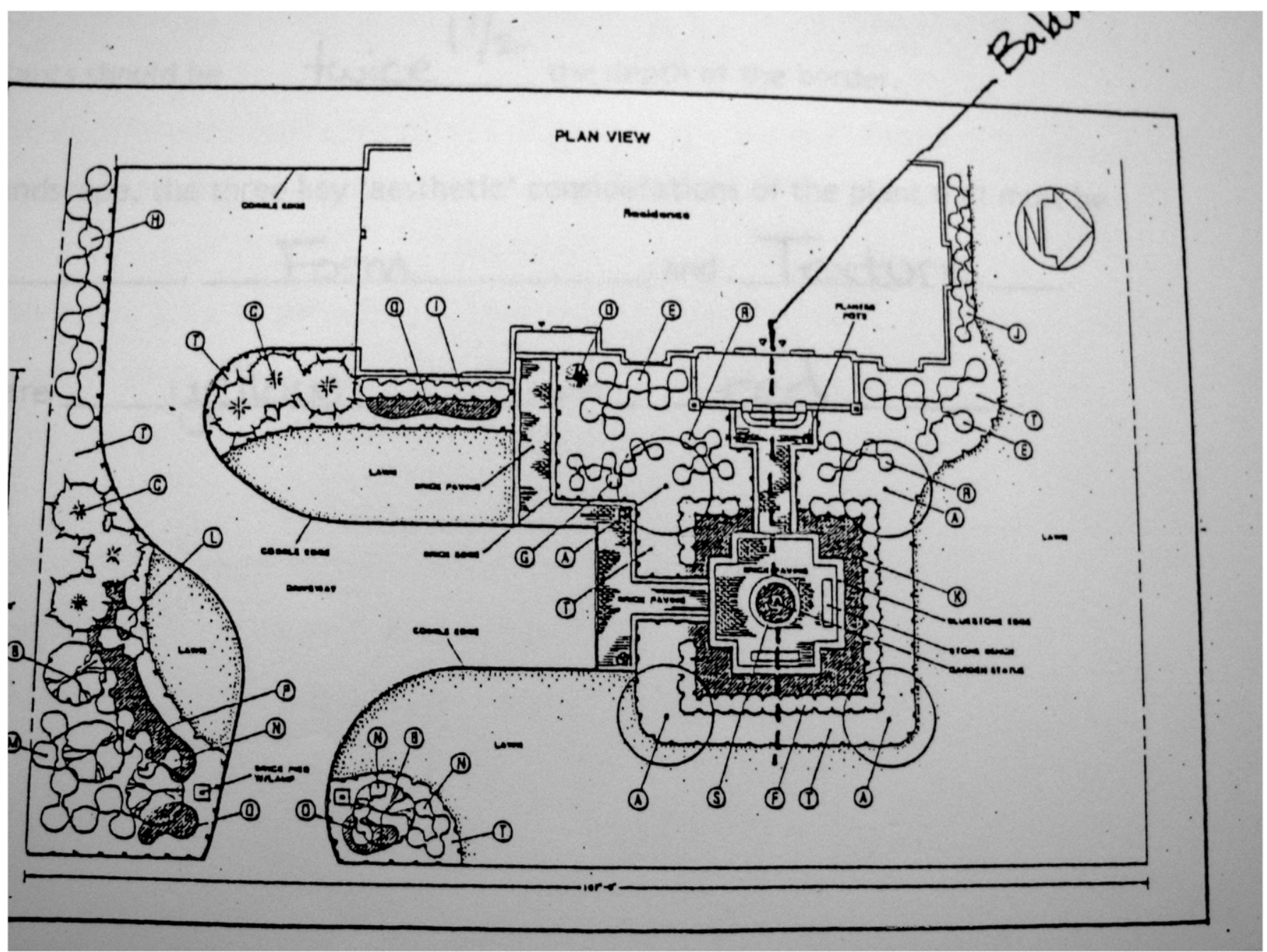

Fig. 3. Landscape plan image used as the 18-point quiz question related to the application of the seven principles of landscape design in the Beginning Garden Composition (HORT 380) course at Iowa State University.

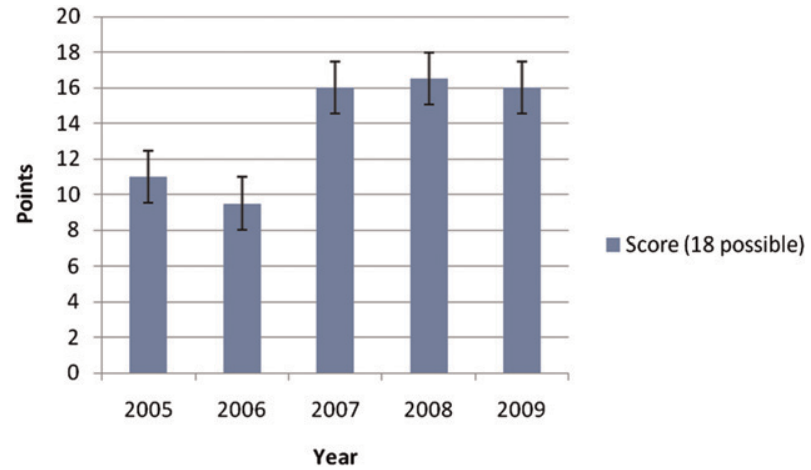

Fig. 4. Student scores on the 18-point quiz question related to the application of the seven principles of landscape design in the Beginning Garden Composition (HORT 380 ) course at Iowa State University from spring semesters 2005-2009.

any course. This method of teaching provided an opportunity for the instructor and students to approach a technical subject in a creative and engaging way.

\section{Literature cited}

Beidler, K., J. Iles, S. Nusser, and A.M. VanDerZanden. 2006. Assessing the preparedness of postsecondary graduates en- tering the landscape contracting industry. HortTechnology 16:312-317.

Berle, D. 2007. Employer preferences in landscape horticulture graduates: Implications for college programs. North Amer. Colleges Teachers J. 51:21-25.

Bloom, B.S., M.D. Engelhart, E. Furst, W.H. Hill, and D.R. Krathwohl. 1956. Taxonomy of educational objectives. Handbook 1: Cognitive domain. Longman, New York, NY.

Boyd, B.L., K.E. Dooley, and S. Felton. 2006. Measuring learning in the affective domain using reflective writing about a virtual international agricultural experience. J. Agr. Educ. 47:24-32.

Hatton, N. and D. Smith. 1995. Reflection in teacher education: Towards definition and implementation. 8 Sept. 2009. $<$ http://alex.edfac.usyd.edu.au/LocalResource/studyl/hattonart.html>.

Landscape Management. 2003. 2003 State of the industry report. 14 Sept. 2009. 
$<$ http://www.landscapemanagement.net/ landscape/article/articleDetail.jsp?id= 70209>.

Lindner, J.R., T.H. Murphy, and G.T. Wingenbach. 2002. Written communication competencies: Strengths and weaknesses of agricultural education graduate students. Proc. Natl. Agr. Educ. Res. Conf., Las Vegas, NV.

Litke, R.A. 2002. Do all students 'get it'? Comparing students' reflections to course performance. Michigan J. Community Service Learning 8:27-34.

McCormick, D.F. and M.S. Whittington. 2000. Assessing academic challenges for their contribution to cognitive development. J. Agr. Educ. 41:114-122.

Moss, L.E., W.D. Seitz, W.R.Q. Anton, and T.E. Anton. 2002. Learning styles, student centered learning technique and student performances in agricultural eco- nomics. North Amer. Colleges Teachers J. 46:34-38.

VanDerZanden, A.M. 2005. An integrated approach to enhance critical thinking skills in a landscape construction course. North Amer. Colleges Teachers J. 49:53-55.

Walkington, J., H.P. Christensen, and H. Kock. 2001. Developing critical reflection as a part of teaching training and teaching practice. Eur. J. Eng. Educ. 26:343-350. 